\title{
ESQUIZOFRENIA CATATÔNICA: UM RELATO DE CASO
}

\author{
Matheus Mitsuo de Souza Kasai, Nicole Cirilo Ducci ${ }^{1}$, Taynara Melchior Fratoni ${ }^{1}$, Aline Aparecida Buriola ${ }^{1,2}$ \\ ${ }^{1}$ Universidade do Oeste Paulista, Curso de Medicina. ${ }^{2}$ Curso de Enfermagem, Presidente Prudente, SP, Brasil. E-mail: \\ aliburiola@gmail.com
}

\section{RESUMO}

A esquizofrenia é um transtorno psicótico que se caracteriza por déficits no neurodesenvolvimento, que acarretam prejuízos no funcionamento pessoal, social, acadêmico ou profissional do indivíduo. A catatonia pode vir associada a diversos transtornos do neurodesenvolvimento, atingindo cerca de $35 \%$ das pessoas com esquizofrenia, e, é caracterizada pela perturbação psicomotora acentuada que pode envolver atividade motora excessiva e peculiar. Assim, este estudo objetiva apresentar um caso de uma jovem com quadro clínico característico de esquizofrenia catatônica, a qual começou com obsessões por operações matemáticas, ouvia vozes ameaçando-a caso não solucionasse as operações. Tinha obsessão também por tomar banho e lavar as mãos. Durante sua internação apresentava episódios catatônicos, não contactuava, não possuía expressão facial, apresentava-se em posição ortostática e em mutismo. Houve melhora do quadro com internação e uso de benzodiazepínico e neurolépticos.

Palavras Chave: Esquizofrenia, Transtornos Mentais, Transtornos Psicóticos, Esquizofrenia Catatônica, Medicina.

\section{CATATONIC SCHIZOPHRENIA: A CASE REPORT}

\begin{abstract}
Schizophrenia is a psychotic disorder that is characterized by a neurodevelopment deficit, what brings losses in the personal, social, academic and professional operations. The catatonia can be associated with various neurodevelopment disorders, affecting $35 \%$ of the schizophrenics, and it is characterized by the accentuated psychomotor disturbance, what can involve an excessive and peculiar motor activity. We present the case of a young girl with a clinical condition of catatonic schizophrenia. It started by an obsession for mathematics operations, she had heard voices threaten her in the case she would not accomplish the operations. She also had obsessions for taking baths and washing hands. During her hospitalization, she had catatonic episodes, of which she did not make contact or any facial expression. She acted in an orthostatic position and did not talk. There was an improvement with the hospitalization and the use of benzodiazepines and neuroleptics.
\end{abstract}

Keywords: Schizophrenia, Mental Disorder, Psychotic Disorder, Catatonic Schizophrenia, Medicine.

\section{INTRODUÇÃO}

De acordo com o Manual Diagnóstico e Estatístico de Transtornos Mentais (DSM V, 2014) $)^{1}$, a esquizofrenia é um transtorno psicótico que se caracteriza por déficits no neurodesenvolvimento, que acarretam prejuízos no funcionamento pessoal, social, acadêmico ou profissional do indivíduo. Delírios, alucinações, discurso desorganizado, comportamento grosseiramente desorganizado ou catatônico ou sintomas negativos, são manifestações características da esquizofrenia. Para fazer o diagnóstico é necessário que o paciente apresente dois - ou mais - desses sintomas, cada um presente por uma quantidade significativa de tempo durante o período de um mês ou mais. Além disso, esses sintomas devem interferir na rotina do paciente, como trabalho, relações interpessoais ou autocuidado. As características psicóticas da esquizofrenia costumam surgir 
entre o fim da adolescência e meados dos 30 anos e sua incidência é menor no sexo feminino.

De acordo com Amaral $^{2}$, o conceito de Esquizofrenia (esquizo $=$ divisão, phrenia $=$ mente) foi elaborado por Eugen Bleuler (18571939), e aparece no título da sua obra Dementia praecox oder Gruppe der Schizofrenien publicada em 1911. Bleuler criou este neologismo para marcar a ruptura de sua concepção com aquela, até então aceita, a concepção da demência precoce de Émil Kraepelin (1856-1926).

Segundo Nardi et $\mathrm{al}^{3}$, Kraepelin, estabeleceu uma classificação de transtornos mentais que se baseava no modelo médico. Seu objetivo era delinear a existência de doenças com etiologia, sintomatologia, curso e resultados comuns. Ele chamou uma dessas entidades de demência precoce (incluindo primeiramente três subtipos clássicos: demência paranóide, hebefrenia e catatonia) porque começava no início da vida e quase invariavelmente levava a problemas psíquicos. Seus sintomas característicos incluíam alucinações, perturbações em atenção, compreensão e fluxo de pensamento, esvaziamento afetivo e sintomas catatônicos.

Segundo Silva et $\mathrm{al}^{4}$, a esquizofrenia é subdividida em tipos, na qual cada uma possui características próprias: A esquizofrenia paranoide caracteriza-se pela presença de ideias delirantes relativamente estáveis, frequentemente de perseguição, em geral acompanhadas de alucinações e de perturbações das percepções. A Esquizofrenia hebefrênica caracteriza-se pela presença proeminente de uma perturbação dos afetos; as ideias delirantes e as alucinações são fugazes e fragmentárias, o comportamento é irresponsável e imprevisível. A Esquizofrenia Catatônica é caracterizada por distúrbios psicomotores proeminentes que podem alternar entre extremos tais como hipercinesia e estupor, ou entre a obediência automática e o negativismo. A Esquizofrenia Residual é caracterizada pela presença persistente de sintomas "negativos" embora não forçosamente irreversíveis. A Esquizofrenia simples caracteriza-se pela ocorrência insidiosa e progressiva de excentricidade de comportamento, incapacidade de responder às exigências da sociedade, e um declínio global do desempenho. Há ainda a esquizofrenia Indiferenciada, Depressão pós-esquizofrênica, outras e não especificadas.
Ainda de acordo com Silva et $\mathrm{al}^{4}$, a esquizofrenia é uma doença que atinge $1 \%$ da população mundial [...], ou seja, aproximadamente 70 milhões da população em todo mundo. Classificado hoje pela psiquiatria como uma síndrome, ela é caracterizada por uma serie de sintomas e sinais que costumam surgir pela primeira vez, na forma de um surto psicótico, por volta dos 20 anos, nos homens, em 25, nas mulheres.

Muitos estudos de esquizofrenias no mundo inteiro constatam que essas taxas variam de um mínimo de 0,6 ao máximo de 17 para cada 1000 habitantes. A maioria dos estudos encontra taxas entre 3 e 10 para cada 1000, NAVES ${ }^{5}$.

No que diz respeito especificamente à catatonia, o DSM $\mathrm{V}^{1}$ diz que ela pode vir associada a diversos transtornos do neurodesenvolvimento e é definida pela presença de três ou mais dos sintomas a seguir: estupor, catalepsia, flexibilidade cérea, mutismo, negativismo, postura, maneirismo, estereotipia, agitação não influenciada por estímulos externos, caretas, ecolalia e ecopraxia. Atinge cerca de 35\% das pessoas com esquizofrenia e é caracterizada pela perturbação psicomotora acentuada que pode envolver atividade motora e participação durante o exame físico diminuídas, ou atividade motora excessiva e peculiar. Durante seus estágios graves, o indivíduo pode precisar de supervisão para evitar autolesão e lesão a outros. Há risco potenciais decorrentes de desnutrição, exaustão, hiperpirexia e lesão autoinfligida.

A esquizofrenia catatônica não tratada pode causar problemas de saúde, financeiros e comportamentais - esses, podem afetar todas as partes da vida do paciente. As complicações podem incluir: depressão; pensamentos suicidas; desnutrição; desidratação; problemas de higiene; abuso de substâncias (que pode incluir álcool, medicamentos prescritos e drogas ilegais); ulceras de pressão, infecções do trato urinário e tromboembolismo venoso. SIENAERT et $\mathrm{al}^{6}$, incapacidade de encontrar ou manter emprego, resultando em pobreza e falta de moradia; conflitos familiares sérios; incapacidade de estudar ou frequentar a escola e outras instituições educacionais. NORDQVIST ${ }^{7}$.

De acordo com a OMS, os serviços de saúde mental devem proporcionar aos pacientes cuidados clínicos relevantes, visando reduzir o impacto da doença mental e melhorar sua Qualidade de Vida (QV). A esquizofrenia é uma 
doença com importante carga financeira e social e afetiva para o paciente, seus familiares e a sociedade. OLIVEIRA et al $^{8}$.

Assim, o objetivo deste estudo é relatar um caso de esquizofrenia catatônica em uma jovem e promover uma discussão a este respeito, visando a confirmação e o estudo de trabalhos já publicados frente à pratica.

\section{RELATO DO CASO}

T.F.G é uma jovem de 19 anos, negra, solteira, evangélica e com ensino médio incompleto. Reside com a mãe, pai, avó e duas irmãs. T. veio ao hospital trazida pela mãe que relata que há cerca de um ano a paciente iniciou quadro de alteração comportamental como retração social, atitudes de mania, alucinações, pensamentos desorganizados com piora há 3 meses, evoluindo para um quadro de mutismo e catatonia. A adolescente já fez tratamento psiquiátrico em 2015 porém não frequentava o acompanhamento no ambulatório de Psiquiatria Infantil como era solicitado. Embora fizesse uso regular dos medicamentos Risperidona e Haloperidol, a mãe relata que a filha só ficava em casa, embaixo das cobertas.

Tímida desde os 8 anos T. não tinha muitos amigos, era reservada. Boa aluna, frequentava a escola normalmente, mas abandonou os estudos aos 17 anos pois a prima que era sua única amiga não estava mais frequentando a mesma escola. Sua infância ocorreu sem anormalidades, até seus 16 anos a família relata que ela era alegre, jogava vídeo game com as primas, adorava cachorros, era obediente em casa e ajudava nas tarefas domésticas. Não tinha contato com vizinhos e não possuía muitos amigos. Sempre retraída e reservada. Nega antecedentes familiares psiquiátricos.

Segundo relato materno, aos 17 anos $\mathrm{T}$. começou com obsessões por operações matemáticas. Ouvia vozes ameaçando-a caso não solucionasse as operações, nestes momentos ficava irritada e ansiosa. Via imagens, vultos, pessoas más e animais peçonhentos como cobras. Paciente fazia troca do dia pela noite pois referia piora das vozes durante o período noturno, também apresentava falta de apetite. Via a si mesma no caixão e a morte de outras pessoas, aumentando seu isolamento. Houve um episódio em que não conseguiu resolver os cálculos dizendo que tiraria a própria vida. Outra obsessão era tomar banho e lavar as mãos, utilizando um pote de creme condicionador por dia e mais de uma barra de sabonete.

A adolescente foi internada pela mãe, apresentando embotamento afetivo em catatonia e edema em membros inferiores com $3+/ 4+$. Foi submetida a exames laboratoriais e análise vascular para avaliar a necessidade de utilização de meias elásticas. Também passa por acompanhamento com fisioterapeuta e nutricionista.

Durante internação relatada neste caso, paciente seguia em estado de catatonia, mutismo, higiene precária, cabelos despenteados e em posição ortostática. Não contactua, não possui expressão facial, necessitando de ajuda para se alimentar e realizar procedimentos de higiene, não apresenta mobilidade nem controle dos esfíncteres, apenas pisca os olhos.

Neste período os profissionais também relataram que as reações da paciente eram irregulares com 0 passar dos dias. 0 comportamento era divergente e haviam dias de progresso onde $\mathrm{T}$. respondia a comandos, apresentava contato visual e era capaz de se alimentar sozinha quando não estava sob observação e em outros dias permanecia catatônica e recusava alimentação. Houveram episódios violentos onde teve que ser mobilizada na cama.

Paciente ficou internada por 74 dias. Seus exames laboratoriais (hemograma, TGO, TGP, uréia, creatinina, sódio, potássio, magnésio e cálcio) não revelaram nenhuma alteração, apresentava Glasgow 15 e bom estado geral. Medicações utilizadas foram: Lorazepam $2 \mathrm{mg} 1$ cp a noite, Olanzapina 5mg $4 \mathrm{cp}$ a noite, Cumarina 15mg + Troxerrutina 90mg 12/12h, Risperidona 3mg 12/12h e Fitoterápico loção para pernas e pés após o banho.

Recebeu alta com o quadro diagnóstico de esquizofrenia catatônica (F20.2). Havendo melhora do quadro, paciente consegue alimentar-se sozinha, contactuar com os olhos e responder alguns sinais. A mãe foi orientada quanto a importância do seguimento ambulatorial e sobre o uso correto das medicações: Lorazepan $2 \mathrm{mg} 1$ comprimido à noite e Olanzapina $5 \mathrm{mg} 4$ comprimido à noite. 


\section{DISCUSSÃO}

A catatonia possui uma prevalência estimada entre pacientes internados psiquiátricos de cerca de $10 \%$, podendo acompanhar muitas doenças psiquiátricas diferentes e doenças somáticas. Uma minoria de pacientes catatônicos sofre de esquizofrenia (30\%), enquanto a maioria possui transtorno bipolar (43\%). Ela também foi associada a outros distúrbios psiquiátricos, como transtorno obsessivo-compulsivo, transtorno de estresse pós-traumático ou retirada de álcool ou benzodiazepínicos. Em até $25 \%$ dos casos, a catatonia está relacionada com condições médicas ou neurológicas gerais. Em adolescentes e adultos jovens com autismo, a catatonia é encontrada em $12-17 \%$. SIENAERT ${ }^{6}$.

A esquizofrenia não pode mais ser tratada como um fenômeno exclusivamente psicológico ou psiquiátrico, uma vez que sua fisiopatologia envolve uma combinação de fenômenos neurológicos e psiquiátricos. WATKINS C.; ANDREWS $S^{9}$. Assim, é correto estudá-la como um distúrbio neuropsiquiátrico. TERRY, A. et al ${ }^{10}$. As partes do cérebro predominantemente envolvidas na esquizofrenia são o prosencéfalo e o sistema límbico. GOGHARI V, et al ${ }^{11}$.

Alguns achados na ressonância magnética de pacientes esquizofrênicos mostram uma redução da substância cinzenta (lobo frontal) e redução da atividade e do volume do cérebro. Os ventrículos e os núcleos basais geralmente são maiores do que o normal, e o hipocampo e a amígdala são menores. HAUKVIK U, et $\mathrm{al}^{12}$.

De acordo com Silveira et al $^{13}$, estima-se que aproximadamente $3,5 \%$ dos dependentes de álcool e outras drogas possuem esse transtorno como diagnóstico psiquiátrico adicional. Pesquisas apontam que as chances de um indivíduo ser portador de esquizofrenia e usar substâncias de abuso são 4,6 vezes maiores que no restante da população. $O$ uso abusivo dessas drogas pode antecipar o início da esquizofrenia, exacerbar os sintomas psicóticos, reduzir a adesão ao tratamento e aumentar os déficits cognitivos, a frequência de recaídas, o risco de suicídio e o de contrair doenças infectocontagiosas, além de intensificar 0 comportamento violento. Sendo assim, pode-se concluir que o abuso dessas substâncias é um fator agravante no que se refere ao prognóstico dos pacientes esquizofrênicos, configurando um desafio no tratamento desta doença.
A Associação Americana de Psiquiatria, diz no DSM $V^{1}$ que os sintomas característicos da esquizofrenia envolvem uma gama de disfunções cognitivas, comportamentais e emocionais, mas nenhum sintoma é patognomônico do transtorno. Podem ser agrupados em duas categorias principais: sintomas positivos, que traduzem um excesso ou distorção das funções normais, e sintomas negativos, que refletem uma diminuição ou perda destas mesmas funções. Os sintomas positivos incluem distorções do conteúdo do pensamento (delírios), da percepção (alucinações), da linguagem e do processo cognitivo (desorganização discursiva) e do autocontrole do comportamento (desorganização ou catatonia comportamental). Os sintomas negativos incluem restrições da variedade e intensidade de expressões emocionais (embotamento afetivo), da fluência e lógica do pensamento e do discurso (alogia) e da "força de vontade".

Ainda de acordo com o DSM $\mathrm{V}^{1}$, os comportamentos catatônicos envolvem um acentuado declínio na reação e estímulos ao ambiente externo, variando desde a resistência ativa a instruções ou tentativas para ser movimentado - negativismo catatônico - rigidez catatônica, postura catatônica (posturas inadequadas durante longos períodos de tempo); atividade motora excessiva sem sentido, podendo também atingir graus extremos (estupor catatônico).

De acordo com Beluci e Ramalho ${ }^{14}$, uma das principais evidências do prognóstico da esquizofrenia é o prejuízo no ajustamento social, o que pode ser evidenciado pela presença de diversos pacientes que atualmente residem na comunidade, os quais apresentam graves incapacidades e sinais de baixos níveis de funcionamento social. As incapacidades pessoais e sociais, que resultam de estressores somados à vulnerabilidade biológica, são determinadas pela quantidade e tipo de estressores, pela rede de suporte social disponível e, ainda, pela capacidade social de resolver problemas objetivos da vida.

De acordo com Souza ${ }^{15}$ várias linhas de evidência indicam fortemente que a esquizofrenia pode ter origem no desenvolvimento neurológico envolvendo componentes genéticos e ambientais. Diversos estudos epidemiológicos têm demonstrado que a exposição pré-natal de grávidas a fatores 
ambientais, como complicações obstétricas e infecções materna, virais ou bacterianas, promove o aumento da incidência de esquizofrenia na prole quando em idade adulta. Isto sugere que a infecção materna durante a gravidez pode contribuir para a origem da esquizofrenia através de seus efeitos no desenvolvimento do cérebro fetal.

Segundo Silva et $\mathrm{al}^{4}$, os antipsicóticos não constituem o único tratamento da Esquizofrenia, mas são o seu foco principal, devido à eficácia nos sintomas psicóticos. Outros tratamentos devem ser aconselhados, uma vez que a farmacoterapia antipsicótica não cobre todo o espectro sintomatológico da Esquizofrenia. Clínicos e familiares devem trabalhar em conjunto para aumentar a qualidade de vida dos doentes, desenvolvendo estratégias individualizadas e baseadas na prática clínica.

O catatonismo apresenta-se sempre de maneira polimorfa com muitos sinais e sintomas, o que dificulta às vezes, a diferenciação de outras doenças. Provavelmente é produzido por um desequilíbrio no sistema dopaminérgico, serotoninérgicos, noradrenérgicos e colinérgicos nos gânglios basais e no córtex pré-frontal, embora 0 mecanismo exato permaneça desconhecido. SOUZA ${ }^{15}$.

A catatonia não é tratada como uma classe independente, ela é definida pela presença de três ou mais de 12 características psicomotoras nos critérios diagnósticos de catatonia, associado a outro transtorno mental e transtorno catatônico devido a outra condição médica. A característica essencial da catatonia é uma perturbação psicomotora associada que pode envolver atividade motora diminuída, participação diminuída durante entrevista ou exame físico ou atividade motora excessiva peculiar (ASSOCIAÇÃO AMERICANA DE PSIQUIATRIA. DSM V - Manual diagnóstico e estatístico de transtornos mentais 2014).

Silva et $\mathrm{al}^{4}$, dizem que a esquizofrenia é uma psicose crônica idiopática, aparentando ser um conjunto de diferentes doenças com sintomas que se assemelham e se sobrepõem, sendo de origem multifatorial. Portanto, é um transtorno causado por diversos fatores biopsicossociais que interagem, criando situações, as quais podem ser favoráveis ou não ao aparecimento do transtorno. Os fatores biológicos seriam aqueles ligados à genética e/ou aqueles que são devidos a uma lesão ou anormalidade de estruturas cerebrais e deficiência em neurotransmissores. Os fatores psicossociais são aqueles ligados ao indivíduo, do ponto de vista psicológico e de sua interação com o seu ambiente social, tais como: ansiedade muito intensa, estado de estresse elevado, fobia social e situações sociais e emocionais intensas. Enfim, indivíduos com predisposição podem desenvolver a doença quando estimulados por fatores biológicos, ambientais ou emocionais.

Uma variedade de fatores ambientais pode influenciar o curso e prognóstico da patologia. Complicações na gestação e no nascimento, com hipóxia, e idade avançada dos pais, estresse e infecções estão associadas a maior risco de esquizofrenia para o feto. Estudos epidemiológicos denotaram um aumento da prevalência de Esquizofrenia em indivíduos nascidos durante epidemias de $\mathrm{H}$. influenza. A ativação do sistema imunitário resulta num aumento de citocinas em circulação, e esse aumento tem sido observado em indivíduos esquizofrênicos.

Ainda de acordo com Sienaert ${ }^{6}$, todos os medicamentos prescritos devem ser avaliados quanto ao seu potencial para induzir sintomas catatônicos e descontinuados, se possível. Geralmente é encorajado a interromper o tratamento antipsicótico em pacientes com catatonia. Na presença de um estado catatônico, os antipsicóticos de primeira e segunda geração podem contribuir para manter ou piorar o estado catatônico e aumentar o risco de desenvolver Síndrome Maligna Neuroléptica (SNM).

Segundo Sienaert ${ }^{6}$, a catatonia é uma característica frequente da mania delirante, uma síndrome grave caracterizada pelo início rápido de delírio, mania e psicose. Sintomas de catatonia e delírio se sobrepõem, complicando o diagnóstico. Os benzodiazepínicos são o tratamento de primeira escolha para catatonia, independentemente da condição subjacente. Os benzodiazepínicos são moduladores alostéricos positivos dos receptores GABA-A e corrigirão a função GABA-ergica deficiente no córtex orbitofrontal.

Sienaert ${ }^{6}$ diz ainda que a eficácia dos benzodiazepínicos na catatonia é determinada pela dosagem, e as doses de 8 a $24 \mathrm{mg}$ de lorazepam por dia são comuns e são toleradas sem sedação subsequente, especialmente quando instituídas usando doses incrementais diárias. Com uma dose adequada, a resposta 
geralmente é observada dentro de 3-7 dias, mas alguns casos, a resposta pode ser gradual e lenta. Lorazepam geralmente é aceito como um medicamento de primeira escolha, demonstrando uma taxa de remissão de $79 \%$. 0 uso bem sucedido de diazepam, oxazepam ou clonazepam também foi relatado.

\section{CONSIDERAÇÕES FINAIS}

O histórico da paciente e os sintomas apresentados foram decisivos no diagnóstico de esquizofrenia catatônica. Paciente não comparecia ao acompanhamento ambulatorial o que influenciou no agravamento da patologia, as perturbações frequentes do transtorno mental sem tratamento fizeram com que o distúrbio neuropsiquiátrico chegasse ao estado de catatonismo. Paciente teve atividade motora diminuída, declínio na reação a estímulos externos, postura inadequada sendo assim sua integridade física além de mental encontrava-se ameaçada. Como não se alimentava, não fazia higiene pessoal e permanecia em mutismo foi necessária a internação. Paciente ficou internada por 74 dias e recebeu alta após apresentar melhora do quadro.

Acredita-se que a realização desse relato contribui de forma positiva para área médica e ressalta a importância da Atenção Básica para diagnóstico precoce e ainda a importância do acompanhamento ambulatorial evitando pioras e crises. A esquizofrenia requer seguimento a longo prazo e para manter pacientes estáveis e evitar progressos há necessidade de acompanhamento por um profissional de saúde mental. São essenciais os cuidados na atenção básica, orientações familiares, além de terapia medicamentosa para reabilitação psicossocial.

\section{RFERÊNCIAS}

1. DSM - Manual Diagnóstico e Estatístico de Transtornos Mentais (Diagnostic and Statistical Manual of Mental disorders) - DSM-5. 2013; 5.

2. AMARAL, VF. Esquizofrenia: da Dementia Praecox às Considerações Contemporâneas. Revista do NESME. 2014; 11(2): 1-30.

3. NARDI AE; QUEVEDO J; SILVA, AG. Esquizofrenia Teoria e Clínica. Ed. Artmed, 2015.
4. SILVA AM, et al. Esquizofrenia: Uma revisão bibliográfica. Revista UNILUS ensino e pesquisa. 2016; 13(30).

5. NAVES REZ. Esquizofrenia: Cuidando de Possibilidades. Universidade Federal de Uberlândia. 2012

6. SIENAERT, et al. A clinical review of the treatment of catatonia. Front. Psychiatry. 2014; 5: 181. https://doi.org/10.3389/fpsyt.2014.00181

7. NORDQVIST C. Understanding the Symptoms of Schizophrenia. 2017.

8. OLIVEIRA RM, et al. A Realidade de Viver com Esquizofrenia. Rev Bras Enferm. 2012; 65(2): 309$16 . \quad$ https://doi.org/10.1590/S0034$\underline{71672012000200017}$

9. WATKINS C; ANDREWS S. Clinical Studies of Neuroinflammatory Mechanisms in Schizophrenia. Schizophr Res. 2016; 176(1):14-22. https://doi.org/10.1016/i.schres.2015.07.018

10. TERRY A. et al. Tropisetron enhances recognition memory in rats chronically treated with risperidone or quetiapine. Biochem Pharmacol. 2015; 151; 180-187.

11. GOGHARI V. et al. A magnetic resonance imaging family study of cortical thickness in schizophrenia. Am J Med Genet B Neuropsychiatr Genet. $\quad 2015$; 168(8): 660-668. https://doi.org/10.1002/ajmg.b.32354

12. HAUKVIK U. et al. Reduced brain cortical folding in schizophrenia revealed in two independent samples. Schizophr Res. 2014; 154; 333-338

13. SILVEIRA, JLF; et al. Esquizofrenia e o uso de álcool e outras drogas: perfil epidemiológico. Rev Rene. 2014; 15 (3): 436-46.

14. BELUCI T; RAMALHO MM. Uma Análise da Esquizofrenia Frente à Experiência com Paciente Esquizofrênico. Revista Científica Eletrônica de Psicologia. 2013; 6.

15. SOUZA, Daniela Fraga. Neuroinflamação e Esquizofrenia: Avaliação de Parâmetros 
Astrogliais in vitro e in vivo. Universidade Federal do Rio Grande do Sul. Porto Alegre, 2012.

Recebido para publicação em 06/06/2018

Revisado em 27/08/2018

Aceito em 29/03/2019 